\title{
«Se hace lo que se puede y con lo que se tiene a mano»: autoficción y parodia policial en Caballeriza de Rodrigo Rey Rosa
}

\author{
RONALD SÁENZ \\ Universidad de Costa Rica
}

Resumen: Este artículo analiza la novela Caballeriza (2006) de Rodrigo Rey Rosa desde la óptica de la novela neopolicial latinoamericana y más específicamente de su variante centroamericana. En primera instancia repasa la manera en que la novela admite un alejamiento consciente de los subgéneros históricos del género policial clásico. Posteriormente ahonda la deconstrucción que hace la novela de este género a partir de procedimientos estéticos no pertenecientes al dogmatismo del policial, a saber: 1) la autoficción y 2) la parodia policial. Se concluye que la novela aporta nuevos elementos para el estudio de la novela centroamericana de posguerra.

Palabras clave: autoficción, literatura centroamericana, neopolicial, parodia, Rodrigo Rey Rosa.

«Se hace lo que se puede y con lo que se tiene a mano»: autofiction and detective fiction parody in Caballeriza by Rodrigo Rey Rosa

Abstract: This article examines the novel Caballeriza (2006) by Rodrigo Rey Rosa from the point of view of the Latin American detective crime fiction and more specifically of the Central American one. In the first instance, it reviews the way in which the novel admits a conscious distancing from the historical subgenres of the classic detective fiction. Later deepens the deconstruction that makes the novel of this genre from aesthetic procedures that do not belongs to the dogmatism of the classic genre, such as: 1) self-fiction and 2) detective fiction parody. It concludes that the novel provides new elements for the study of the post-war Central American novel.

Keywords: autofiction, Central American literature, neopolicial, parody, Rodrigo Rey Rosa. 
Caballeriza debe ser leída más en clave de farsa que como novela negra. Se hace lo que se puede y con lo que se tiene a mano. Rodrigo Rey Rosa, Imitación de Guatemala.

\section{INTRODUCCIÓN ${ }^{1}$}

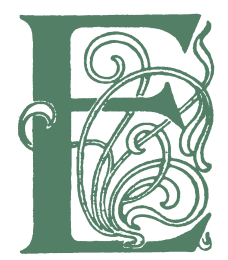

n su momento, el escritor guatemalteco Rodrigo Rey Rosa, fue reconocido por el mismo Roberto Bolaño como un autor que llegó a arrojar «una mirada distinta sobre la novela negra, género en el que todos se atreven y del que muy pocos salen bien librados» (Bolaño, 2004: 33). Esta afirmación se ratifica con la publicación, entre 1995 y el 2006, de cuatro novelas breves que la crítica ha catalogado como policiacas ${ }^{2}$ y que en 2013 fueron reeditadas por Alfaguara en un único volumen titulado Imitación de Guatemala ${ }^{3}$. Sobre la última de ellas - la cual se ha seleccionado para el presente artículo y que viene a completar su Tetralogía de Guatemala - el propio autor ha dicho que «debe ser leída más en clave de farsa que como novela negra» (Rey Rosa, 2013: 9). La anterior afirmación constituyó, sin duda, el principal aliciente para la formulación del problema que atañe a este trabajo.

Este artículo propone el estudio de la novela Caballeriza (2006) de Rodrigo Rey Rosa desde la óptica de la novela neopolicial latinoamericana y más específicamente de la centroamericana. Así, tiene por objeto demostrar que la variante centroamericana aporta elementos novedosos para el estudio del género al menos en dos vías: en primer lugar, la manera en que la novela admite un alejamiento consciente de los subgéneros históricos del policiaco planteados por Gubern (2002), García Talaván (2014) y Sánchez Zapatero (2017). En segunda instancia, la deconstrucción que se lleva a cabo en la novela en lo referente a los procedimientos estéticos que se presumen como no pertenecientes al dogmatismo del policial, esto a través de: 1) escrituras del yo como la recurrencia a la autoficción y 2) al juego lúdico planteado alrededor

\footnotetext{
1 Agradezco los comentarios y recomendaciones de los pares anónimos, los cuales he tomado en cuenta e incorporado en gran medida. Asimismo, a la Dra. Verónica Ríos Quesada, profesora del curso «Literatura Centroamericana» en la Universidad de Costa Rica (I-2017), a quien debo muchas de las discusiones plasmadas en este trabajo.

2 A saber, El cojo bueno (1995), Que me maten si... (1996), Piedras encantadas (2001) y Caballeriza (2006).

3 Las citas de Caballeriza realizadas en este trabajo son todas tomadas de esta edición.
} 
de la investigación policial clásica, o bien, lo que se llamará en este trabajo como parodia policial.

La selección de esta novela invita a reconocerle un valor literario que hasta la fecha parece haber pasado desapercibido: no se ha encontrado un texto de crítica especializada que la trabaje en su especificidad. En su lugar, Caballeriza ha sido abordada de manera residual, es decir, a través de menciones superficiales, anecdóticas o poco desarrolladas, siendo incluso tachada como una novela «mal lograda» (Coello, 2008, 2009; Hernández, 2015; Laorden, 2015; Monterroso, 2011; Perkowska, 2011; Pezzè, 2011; Quintero, 2015).

Pareciera que la novela ha sido de alguna manera desvalorizada, tanto por la academia como por el propio autor (como se aprecia en el epígrafe inicial); la crítica literaria que trabaja los textos de Rey Rosa ha brindado una mayor atención a las novelas cortas precedentes sobre todo en lo referente a las representaciones del espacio y la violencia urbana en el marco de la novela centroamericana de posguerra (véase Hernández, 2015). ${ }^{4}$ De esta manera, puede argumentarse que ha quedado abierto un terreno para el estudio de los procedimientos estéticos presentes en la obra de Rey Rosa que caminan en la dirección de configurar una determinada poética de autor5, observada en la obra novelesca de Rey Rosa no solo en Caballeriza sino también de manera posterior en El material humano (2009) ${ }^{6}$, novela con la cual dialogará en términos éticos y estéticos, dilucidando diversas perspectivas de la violencia estructural implantada en la realidad guatemalteca contemporánea.

Así, la importancia de reclamar un espacio para Caballeriza reside, entre otras cosas, en el interés de analizar su estructura lúdica e intentar develar algunos mecanismos que componen «la farsa» que señala el propio Rey Rosa,

\footnotetext{
4 En una entrevista concedida a Raúl Rodríguez Freire, Rey Rosa afirma que las representaciones de la violencia urbana pueden conllevar el defecto potencial de estereotipar la literatura centroamericana: «[...] hay algo negativo en esa obsesión con la novela urbana. El campo, "el interior" se deja en la trastienda y ya no se puede tematizar... y eso me parece absurdo, yo sí creo que sigue siendo un tema tan válido y vigente como la vida urbana. Y no me parece muy bien que mi obra se lea más o resuene más bien en ese contexto de la pura violencia, a pesar de que he escrito bastante sobre otros temas [...]» (Rodríguez Freire, 2011: 1077). Esta afirmación aporta otro aliciente para el estudio de Caballeriza.

5 Scarano (2017: 140-141) entiende por poética de autor a un tipo de «escritura o representación del yo» de carácter autoreflexivo sobre la labor de ficcionar dentro de la propia obra de ficción, que vincula al texto $\mathrm{y}$ al autor con un uso privilegiado de la primera persona.

6 Es importante recalcar que los trabajos de Coello (2009) y Monterroso (2011) ya se han preocupado por adelantar algunas preocupaciones referentes a esta línea.
} 
siendo que puede llegar a brindar un aporte tanto para la teoría como para la crítica referente al autor. Se sostiene que la auto desvaloración expresa en este epígrafe por una parte desencadena interrogantes en torno a los elementos que podrían ayudar a leer (o no) a Caballeriza como un texto policiaco desde una lectura tradicional. Por otra, provoca inquietudes transversales que engloban una determinada forma de narrar y de cuestionar la misma narración, en suma, una «voluntad de jugar con el lector» bastante distintiva del género (Sánchez Zapatero, 2017: 123).

La primera sección del trabajo estará dedicada a establecer un breve repaso por lo que se ha dado en llamar la narrativa neopolicial latinoamericana como marco para desarrollar el nivel de inserción de su variante centroamericana dentro de la obra de Rey Rosa.

De manera posterior se propone estudiar los procedimientos estéticos presentes en la novela y que en consecuencia se alejan del dogmatismo del policial clásico; de esta manera el artículo explora el posible diálogo entre los conceptos centrales de autoficción y parodia (de la investigación policial clásica) como ejes de lectura que se configuran al menos en un par de textos de Rey Rosa y que buscan dilucidar el constante juego de escamoteo ya sea metaliterario, o bien paratextual, articulado alrededor de la novela estudiada.

\section{EL NEOPOLICIAL COMO SUBGÉNERO EN CONSTANTE (DE) CONSTRUCCIÓN: LA VARIANTE CENTROAMERICANA}

El término neopolicial ${ }^{7}$ es hoy comúnmente utilizado por varios autores para hacer referencia a la producción de novela policial en América Latina sobre todo a partir de la década de los setenta (García Talaván, 2014; Martín y Sánchez, 2007; Noguerol, 2006; Padura, 1999). Durante ese decenio surgieron las primeras novelas que enmarcarían de manera prominente la producción posterior.

Para el afamado escritor cubano de neopolicial, Leonardo Padura, este auge presenta desde su origen «una insatisfacción hacia todas las propuestas

\footnotetext{
7 «Término acuñado por Paco Ignacio Taibo II en 1990 para designar la clase de prosa que desde hacía algunos años venían practicando escritores de origen latinoamericano como Mempo Giardinelli, Ramón Díaz Eterovic, Leonardo Padura Fuentes y el mismo Taibo» (García Talaván, 2014: 72). En este trabajo se utiliza el concepto como parte de un continuo narrativo que tiene a la novela policial clásica y a la novela negra como principales precedentes.
} 
antirrealistas y las copias burdas o las parodias fáciles que se habían extendido hasta la literatura policiaca de principio de los 60» (Padura, 1999: 42). Lo anterior significó una toma de posición evidente con respecto del género en particular, sobre todo tomando en cuenta el peso de la tradición, siendo que «el género policiaco en Latinoamérica no surge como hecho aislado, sino que proviene de dos grandes tradiciones escriturales, respectivamente la escuela inglesa con la denominada novela enigma y la escuela norteamericana con la novela negra» (Soto, 2016: 1).

A este respecto, García Talaván (2014: 85) parte de una posición clara: «la novela policial ha sido capaz de transformarse y adaptarse a distintos contextos y épocas». ${ }^{8}$ La autora sostiene que desde los primeros atisbos del género en los relatos de Edgar Allan Poe pueden llegar a ubicarse algunos «subgéneros históricos precedentes» de la variante latinoamericana y provenientes de las grandes metrópolis, como se aprecia en el siguiente cuadro.

\begin{tabular}{|l|l|l|l|}
\hline $\begin{array}{l}\text { Cuadro 1. Subgéneros históricos precedentes de la narrativa policial } \\
\text { latinoamericana. }\end{array}$ \\
\hline Subgénero & $\begin{array}{l}\text { Novela policial } \\
\text { clásica o «nove- } \\
\text { la-enigma». }\end{array}$ & $\begin{array}{l}\text { Novela policial } \\
\text { negra o hard-boiled. }\end{array}$ & $\begin{array}{l}\text { La novela policial } \\
\text { psicológica o cos- } \\
\text { tumbrista. }\end{array}$ \\
\hline $\begin{array}{l}\text { Exponentes más } \\
\text { reconocidos }\end{array}$ & $\begin{array}{l}\text { Edgar Allan Poe, } \\
\text { Arthur Conan } \\
\text { Doyle, Agatha } \\
\text { Christie y G.K. } \\
\text { Chesterton. }\end{array}$ & $\begin{array}{l}\text { Dashiell Hammett, } \\
\text { Raymond Chan- } \\
\text { dler, Horace Mc- } \\
\text { Coy, entre otros. }\end{array}$ & $\begin{array}{l}\text { Georges Sime- } \\
\text { non, Pierre Véry y } \\
\text { Claude Aveline. }\end{array}$ \\
\hline $\begin{array}{l}\text { Componente } \\
\text { predominante }\end{array}$ & $\begin{array}{l}\text { Estético. } \\
\text { Ético. }\end{array}$ & $\begin{array}{l}\text { A medio camino } \\
\text { entre los dos an- } \\
\text { teriores, pero más } \\
\text { cerca del estético. }\end{array}$ \\
\hline Periodización & $\begin{array}{l}\text { Segunda mitad del } \\
\text { siglo XIX y prime- } \\
\text { ras décadas del XX. }\end{array}$ & $\begin{array}{l}\text { Segunda década } \\
\text { del siglo XX y } \\
\text { postcrisis del 29. }\end{array}$ & $\begin{array}{l}\text { Post II Guerra } \\
\text { Mundial. }\end{array}$ \\
\hline Fuente: Elaboración propia con base en García Talaván (2014: 68-70). \\
\hline
\end{tabular}

8 En una formulación similar, Mariana Soto (2016: 1) afirma que «El policial no se crea ni se destruye, solo se transforma». 
García Talaván parte del recuento sintetizado en el Cuadro 1 para apoyar su tesis sobre la constante transformación del género, esto con el fin de llegar a lo que supondría un cuarto subgénero propuesto, a saber, la narrativa neopolicial latinoamericana. Al ofrecer detalle sobre las características de este último subgénero, se dedica un mayor énfasis a la revuelta ética y estética que supuso el surgimiento de este particular cuarto subgénero, arguyendo que el neopolicial latinoamericano llega a equilibrar ambos ejes (ético/estético) a través de un discurso revisionista histórico y una estética que, entre otras cosas, tiende a la adaptación paródica de estructuras novelescas y al «reflejo de la realidad plural, diversa, caótica y violenta [...] con el fin de destacar los problemas de sus sociedades actuales y, al mismo tiempo, cuestionar el discurso del poder» (García Talaván, 2014: 74). Leonardo Padura coincide con esta postura y asevera que estos procedimientos han sido asumidos por la nueva estética del neopolicial misma, que entre otras cosas

se acerca notablemente al documento periodístico - e incluso lo practica - y rebasa muchas veces la verosimilitud, militando abiertamente en el terreno de la crónica [...] [demuestra] afición por los modelos de la cultura de masas, su visión paródica de ciertas estructuras novelescas, su propia creación de estereotipos, el empleo de los discursos populares y marginales, y el eclecticismo, el pastiche, la contaminación genérica, y esa mirada superior, francamente burlona y desacralizadora, que lanzan sobre lo que, durante muchos años, fue la semilla del género: el enigma. (Padura, 1999: 41)

Ahora bien, a las características que engloba Padura, pueden agregárseles otras más al momento de estudiar el neopolicial producido en la región centroamericana. Hoy día ya son varios los autores que respaldan el hecho de que la variante centroamericana del mencionado subgénero latinoamericano comienza a demostrarse y afianzarse a partir de la década de los noventa (Kokotovic, 2003, 2006, 2012; Laorden, 2015; Pezzè, 2018; Quesada, 2012a, 2012b; Rivera, 2014). ${ }^{9}$ Este hecho coincide, a nivel sociopolítico, con los procesos de transición desde gobiernos autoritarios y los esfuerzos para establecer la paz en la región, la cual estuvo sumida en una espiral de violencia

9 Es común situar a Castigo divino (1988) del escritor nicaragüense Sergio Ramírez (Premio Cervantes 2017) como la precursora del género en Centroamérica. Su importancia es tal que en 2018 es reeditada por Alfaguara tras cumplir 30 años desde su primera aparición. 
producto de las guerras civiles, las violaciones sistemáticas a los derechos humanos y el genocidio indígena. ${ }^{10}$

Con este clima abrumador como telón de fondo, la literatura centroamericana de la posguerra ha sido leída y estudiada como parte de la estética del cinismo Cortéz $(2000)^{11}$, haciendo alusión a la confluencia entre el clima de desasosiego producto de la traumática coyuntura bélica, la restauración de la institucionalidad civil, el juego electoral, la impunidad militar y la inauguración de la agenda económica neoliberal en la zona.

Bajo este marco, no es de extrañar que mucha de esta nueva literatura retrate de manera eficaz un tejido social en descomposición en el que las grandes asimetrías sociales siguen prevaleciendo luego del final de las utopías revolucionarias. Esta narrativa es el retrato de sociedades que no han visto cumplida la promesa del ajuste económico, al contrario, el añorado bienestar social no llegó de la mano de la apertura al mundo, ni del retorno de los militares a los cuarteles, ni siquiera de las elecciones libres y periódicas; esta literatura, en conjunto ofrece una visión desencantada de la sociedad que ha sobrevivido los embates de las guerras civiles y en la que «la violencia lo permea todo hasta constituirse incluso en una forma de identidad, en tanto la ley y la justicia son solamente mamparas de otros intereses» (Quesada, 2012: 173).

La década de los noventa también resquebrajando la hegemonía de la narrativa testimonial, la cual entre los sesenta y ochenta del siglo se caracterizó por dinamizar la circulación, el consumo, la crítica y la producción de textos narrados por los llamados sujetos populares. Esta se fue haciendo habitual a medida que, en el aquel entonces mentado Tercer Mundo, se desarrollaban conflictos armados internos y enmarcados, en su mayoría, bajo la bipolaridad que abrazó el planeta a raíz de la Guerra Fría.

\footnotetext{
10 Los casos emblemáticos Centroamérica han sido los de El Salvador y Guatemala. Ambos países encabezan la lista latinoamericana en torno a violaciones de derechos humanos en periodos represivos, alcanzando juntos un estimado de 550.000 muertos o desaparecidos (Martínez-Barahona, Gutiérrez y Rincón, 2012). Aunque los demás países del Istmo no experimentaron una coyuntura en estos términos, sí es posible de hablar de una región que compartió las secuelas del conflicto, a saber: la política exterior de los Estados Unidos y la Unión Soviética, el tráfico de arsenal de guerra, la afluencia de grupos armados, los desplazamientos forzosos, entre otros.

11 Para Cortéz, «[...] esta ficción retrata a las sociedades centroamericanas en estado de caos, corrupción y violencia. Presenta sociedades pobladas por gente que define las normas de la decencia, el buen gusto, la moralidad y la buena reputación, y que luego las rompe en su espacio privado» (Cortéz, 2000: 2).
} 
Para aquel género testimonial, el narrador o narradora se presumía como fiel representante de una colectividad que enmarcaba su alegato dentro de un proyecto político mayor; estos son los casos de los textos canónicos de Omar Cabezas (1982) en Nicaragua, Manlio Argueta (1985) en El Salvador o Rigoberta Menchú (1985) en Guatemala. No obstante, al lado de estos trabajos y sobre todo luego de las transiciones a la democracia, en la región también aparecen relatos narrados en primera persona que se llegan a valer de algunos de los elementos clásicos del género testimonial centroamericano - véase Beverley (1987) - , pero ahora con miras a reformularlos, partiendo de nuevos procedimientos formales y estéticos.

Hay evidencia de fuertes rupturas con características esperadas en el pasado para los textos narrados en primera persona, a saber: i) su punto de vista no es precisamente desde abajo, ii) no hay radicalización o toma de conciencia - como las interpretaciones ad hoc que se llegaron a proponer en la línea de la Bildungsroman para las llamadas novelas de guerrilleros (Leyva, 2016) - , iii) tampoco plantean situaciones de represión experimentadas por los protagonistas; en suma, ya no se plantean como novelas de tesis.

La inserción de otros sujetos diferentes de los populares en el universo de las narraciones permite acceder a un nuevo punto de vista: se está ante un panorama ambiguo y complejo que contrasta con la función directiva y catártica del testimonio tradicional. Por el contrario, la inmersión en el recurso de la autoficción se adapta a sociedades individualistas que entran en constante diálogo con la subjetividad de los autores; a diferencia del testimonio, «el yo» ya no «se funde en el sujeto colectivo», es decir, deja de ser «un yo que representa» un determinado proyecto (Pozo, 2017).

Lo anterior responde en gran medida a los signos de época que comenzaron a marcar cambios drásticos sociales en las sociedades centroamericanas - Kokotovic (2006) incluso habla de «policial neoliberal»-. La narrativa centroamericana más contemporánea fue ganando diversidad temática y propositiva al tiempo que fue perdiendo interés para la academia - sobre todo norteamericana - en la región otrora identificable con el testimonio. ${ }^{12}$

La llamada «vuelta a la ficción» de las letras centroamericanas, o lo que Alexandra Ortiz-Wallner ha identificado como una «apuesta novelística por

12 A este respecto, véase Guzmán-Medrano (2013). 
la recuperación de un arte de ficcionar distanciado, muchas veces en clave paródica o irónica, del modelo testimonial y de las narrativas de los procesos revolucionarios» (Ortiz-Wallner, 2012: 17-18), ha venido ganando terreno, siendo que «la realidad se vuelve pretexto/pre-texto para poder escribir literatura, la literatura ya no es más subterfugio para poder hacer política» (Mackenbach, 2007: párr. 22). Esto no indica ni mucho menos un «repliegue intimista» de las letras centroamericanas de la posguerra, en su lugar: «más que el abandono de la política, la nueva narrativa podría simplemente estarla planteando de otra forma» (Leyva, 2016: 64).

Así, en Centroamérica el género neopolicial encontró un clima ideal para desarrollar apuestas estéticas y reflexionar en torno a las sociedades resultantes, tanto de los proyectos de paz y la recomposición social, como de las reformas económicas amparadas por el dogmatismo monetarista llevadas a cabo en todos los países de la región de manera más o menos generalizada. ${ }^{13}$ Bajo esta tradición ha sido estudiada una gran parte de la obra de Rodrigo Rey Rosa - y de otros autores como Horacio Castellanos Moya, Dante Liano, Franz Galich, Jacinta Escudos y Claudia Hernández, entre otros - misma que para el caso de Guatemala ha «explorado con mayor agudeza las complejas relaciones entre poder, violencia y espacio físico», con una escritura que subvierte «constantemente los esquemas ideológicos y estéticos de los cuales parte» (Quesada, 2012: 175).

Todo lo anterior es observable en Caballeriza, «novelita» breve que relata la experiencia de un escritor - el propio Rey Rosa o su desdoblamiento literario, su «yo autoficticio»- alrededor de un atentado presenciado por el protagonista durante una fiesta equina ofrecida por y para la aristocracia guatemalteca. La muerte de un equino pura raza, propiedad del gamonal local don Guido Carrión durante la celebración de su octogésimo octavo aniversario, desencadena el curso de la narración y de la investigación que llevará al protagonista a involucrarse de lleno con la resolución del atentado. Es de destacar que, desde el íncipit se está ante la presencia de elementos metaficcionales y autoficcionales que llevan tanto al autor como al lector a cuestionarse constantemente por la naturaleza del texto. Estos elementos serán profundizados durante la siguiente sección.

13 En esta línea, Hernández (2015) ha llegado a establecer un paralelismo entre las condiciones presentes en la obra del autor guatemalteco y el fenómeno de la llamada narconovela, la cual ha tenido reformulaciones particulares en países como Colombia y México. A este respecto véase Bouvet (2015) y Michael (2013). 
Dado el argumento general, el cual en apariencia responde a una estructura clásica policial (1. un crimen, 2. perpetuado en el contexto de una celebración de la élite política y económica, y 3 . una investigación en torno al mismo), esta va a ser frecuentemente violentada a medida que la voz narrativa se comienza a confundir con la propia del autor, a medida que la muerte del caballo andaluz permite observar dinámicas desiguales persistentes en una supuesta Guatemala democrática, o bien, el alejamiento de la trama criminal del contexto urbano ${ }^{14}$. En lo siguiente, el análisis desarrollará las evidencias estéticas que permiten observar tanto esta recurrencia a la autoficción como al juego lúdico de la investigación criminal.

\section{UN ESCRITOR EN BUSCA DE UN TEMA. AUTOFICCIÓN EN CABALLERIZA}

A muchos escritores les pasó: en el momento menos pensado un desconocido se aproxima y les dice: "Debería usted escribir algo acerca de esto». Generalmente la operación no resulta, pero yo estaba en busca de algún tema para ponerme a escribir, y la idea me pareció interesante.

Rodrigo Rey Rosa, Caballeriza.

Para comenzar, es importante plantearse la siguiente pregunta: «ipuede uno partir de un hecho de su propia vida y, en determinado momento, continuar el relato incorporando elementos de ficción?» (Monterroso, 2011: 122). Esta pregunta no es del todo novedosa, sobre todo si se toma en cuenta que la tendencia a equiparar hechos de la vida personal de determinado autor con aquellos narrados en su obra es una tentación siempre latente tanto para la crítica literaria como para los lectores. ${ }^{15}$

\footnotetext{
14 En diálogo con la nota al pie $\mathrm{n}^{\circ}$. 4, de manera reciente se habla de la proliferación del country noir en Estados Unidos y Europa, subgénero entendido como un impulso renovado de ambientar las novelas negras en contextos rurales, pero sin afanes costumbristas: «funciona de alguna manera como reverso oscuro de esa vuelta al campo, como una versión en negativo sin concesiones, libre de idealizaciones. Una mirada descarnada que no por opuesta niega la otra» (Galindo, 2018, párr. 5).

15 Cuando se aborda el tema de la autoficción desde el punto de vista del lector se está ante una situación más problemática en tanto «desde el punto de vista del lector ingenuo, del lector que se acerca al libro en busca de un rato ameno, nos podríamos preguntar si existe en realidad la autoficción, o incluso la autobiografía, o si es posible marcar de forma estricta los límites de la Historia con la historia como relato (y por tanto como ficción)» (Pozo, 2017: 16).
} 
Hacia finales la década de los setenta se empieza a acuñar el concepto de autoficción para referirse a este recurso literario pero ahora como género independiente con características particulares y que aludía precisamente al punto de encuentro verificable entre la autobiografía, la realidad y la ficción; siendo la autoficción «un trabajo que mezcla hechos de la vida del autor y la imaginación» (Monterroso, 2011: 121-123), el cual busca generar un carácter intimista con el lector, por un lado mostrándole que los hechos narrados sucedieron en la realidad, pero a su vez agregándole elementos ficcionales para que este no se apegue tanto a ellos y los asuma como parte de la construcción misma de la novela.

En consonancia, Alberca plantea que la autoficción «es un relato que se presenta como novela, es decir como ficción [...] se caracteriza por tener una apariencia autobiográfica, ratificada por la identidad nominal de autor, narrador y personaje» (Alberca, 2005: 5-6). Es decir, en este género se sintetizan los rasgos de la autobiografía y la novela, configurando un estilo particular de escritura.

Desde esta visión existiría un desdoblamiento entre el Rey Rosa que como novelista se dedica a contar y a analizar una realidad determinada de la Guatemala contemporánea, valiéndose de un narrador protagonista claramente identificable con él mismo e insertándose en la narración, en este caso por medio de su apellido, por guiños biográficos, o bien posteriormente por alusión directa de su obra narrativa precedente. ${ }^{16}$

Es importante traer a discusión el hecho de que este mismo fenómeno puede resultar de interés desde distintos posicionamientos teóricos. Rosales (2016) analiza la figura de Rey Rosa desde sus «configuraciones y autoconfiguraciones», es decir, estudia la imagen de autor con base en sus propias proyecciones (entiéndase, cómo se concibe a sí mismo tanto desde su oficio de escritor, lo que denomina ethos autorial, y cómo se concibe dentro de su obra de ficción, lo que denomina ethos del narrador) y con base en las proyecciones de terceros (cómo lo concibe la prensa, la crítica y otros escritores).

\footnotetext{
16 Como se adelantó en la introducción, Rey Rosa vuelve a este recurso en El material humano (2009), novela protagonizada por el mismo narrador de Caballeriza. En esta segunda novela el narrador hace alusión a la anterior: «Hoy a las siete de la noche, en el Centro de Cultura Hispánica de Cuatro Grados Norte, presentación de mi novelita Caballeriza. Pese a que no quiero ir iré. Esta parte del trabajo, la presentación a la prensa o al público ("ese monstruo", como dice W.H. Auden), es para mí la más incómoda y la menos grata; y en el caso de este relato "realista" en primera persona el aspecto incómodo se magnifica» (Rey Rosa, 2009: 81-82).
} 
En diálogo con la propuesta del presente trabajo, resulta sugestivo el concepto ethos del narrador ya que este verifica los posicionamientos del autor-protagonista en vinculación con la realidad social circundante o, para este caso, con su (auto)cuestionada inserción dentro de la tradición de la literatura guatemalteca.

El contexto, entonces, es un elemento base para la inserción del yo autoficticio $^{17}$, inmerso en un ambiente en el que converge el papel de su propio rol como escritor consagrado con su vida íntima y familiar y hasta con sus propios universos narrativos. A este respecto, Rey Rosa hace énfasis en la espontaneidad y en la importancia de la trama, como precondición para optar por una narrativa autoficcional:

Es a medio camino que me doy cuenta de mi situación, estaba ya con un texto de unas 50 páginas, y de pronto me doy cuenta de que eso es el principio de la novela. Entonces es una aventura muy divertida, a veces aterradora porque está el miedo y hay una invención de trama ... Creo que sólo una de las personas que lo ha reseñado habla de que hay una trama y que yo me apego a la trama y creo que eso es cierto, porque aunque está hecho digamos que de "hilachas de realidad", es ficción sin duda porque hay una trama... hay una trama a partir de cierto momento en que sé que lo que estoy escribiendo no es un diario, estoy escribiendo una novela donde dejo que todas mis circunstancias coincidan con las del personaje, pero es ficción. Por eso yo digo en serio que es ficción: "Aunque no lo parezca, aunque no quiera parecerlo, ésta es una obra de ficción". (Rodríguez Freire, 2011: 1081).

Como se muestra en el epígrafe de esta sección, en Caballeriza el pacto ficcional presupuesto entre el autor y el lector es violentado desde las primeras páginas a su vez que articula una vertiente narrativa que atravesara todo el texto: «Es el hijo de Rey Rosa, el textilero. Vino con él a tu fiesta. Te regaló un caballito de barro» (Rey Rosa, 2013: 262). Es a través del narrador protagonista -el hijo de Rey Rosa, el textilero- que se da a conocer la trama que rodea la situación familiar de Los Carrión:

17 Este es definido por Alberca: «El yo autoficticio es un yo real e irreal, un yo rechazado y un yo deseado, un yo auto biográfico e imaginario. Todos los yos caben en él: el yo mitómano y el yo verdadero, el megalómano y el ecuánime, el consciente y el inconsciente de su propia invención. No renuncia a nada, pues está abierto a toda clase de metamorfosis personales y de suplantaciones fantásticas, que le convierten en otro sin dejar de ser él mismo, es decir, sin dejar de saber que yo es y no es otro» (Alberca, 2007: 92). 
En la década de 1960 mi padre, que anda hoy por los ochenta, había traído a Guatemala un semental andaluz de la cuadra de Álvaro Domecq - el Pregonero, todavía recordado en «el ambiente» como el primer purasangre español importado a la pequeña república. Así, en el amplio círculo ecuestre guatemalteco, a mi padre lo consideraban el precursor en materia de caballos españoles, y todavía le rendían cierta pleitesía. (Rey Rosa, 2013: 233).

Por medio de él, se construye el halo negro que rodea a esta familia gamonal, el protagonista llena el texto con observaciones y opiniones; por medio de esta construcción del yo autoficticio se logran desenmarañar, en suma, los secretos endogámicos, la sed de venganza del nieto y la falta de escrúpulos de don Guido Carrión, quien no duda en asesinar a su propio nieto para mantener en secreto la verdad sobre este crimen. Este recurso cruza transversalmente Caballeriza y refuerza una visión sobre la situación de la burguesía criolla guatemalteca, en donde se busca encubrir todo lo que pueda afectar su jerarquía.

El narrador a su vez se convierte en una suerte de antropólogo; en una suerte de ejercicio etnográfico desgrana tanto el complejo sistema de estratificaciones sociales y de raigambre colonial que pervive en Guatemala como la matriz de violencia arraigada presente en el ambiente ${ }^{18}$ :

Los caballerizos estaban uniformados con trajes festivos [...] He aquípensé - la parte más amplia de la pirámide [...] En la segunda capa de la pirámide se encuentran los hombres de seguridad. Muchos de ellos también hubieran podido vestir indumentaria quiché o tzutuhil sin llamar la atención, pero iban en traje de calle, tocados con el sombrero texano todavía en boga en las fincas de la región. Casi todos llevaban al hombro escopetas recortadas y, al cinto, cananas con cartuchos de varios colores. [...] Una capa más arriba supongo que estarían el animador, los músicos y las edecanes [...] La escasez de mujeres hacía pensar en una reunión de jeques árabes. Se diría que no llevar una pistola visible al cinto o bajo la axila era una falta de etiqueta - falta que parecía perdonable sólo a los muy viejos. Entre los jóvenes, muchos llevaban, además de la automática oscura y reluciente, algunas recámaras de reserva -como si esperaran que

\footnotetext{
18 Es inevitable no establecer un paralelismo entre el ejercicio que realiza Rey Rosa en la novela y el reconocido ensayo del sociólogo guatemalteco Edelberto Torres-Rivas (2008) titulado «Guatemala 2000: un edificio de cinco pisos». Aunque con recursos evidentemente diferentes, ambos autores plantean un análisis de la estratificación social en Guatemala con base en las características étnicas de su población.
} 
tarde o temprano se produjera un tiroteo y hubieran previsto el peligro de quedarse sin balas (Rey Rosa, 2013: 233-234).

Además, también deja claro el carácter carnavalesco de la actividad en tanto menciona que, a pesar de tantas diferencias reunidas «de clase, de profesión, de ideología o superstición», este tipo de celebraciones provoca una suspensión momentánea de las jerarquías:

Me pareció ver un rasgo positivo en aquel microcosmos de la sociedad guatemalteca en el hecho de que ahí, hermanados por las inclinaciones equinas, parecía que todos olvidaban cordialmente muchas diferencias de clase, de profesión, de ideología o superstición - que en otras circunstancias habrían impedido que gente tan dispar se congregara de manera festiva. (Rey Rosa, 2013: 234).

El yo autoficticio de la novela se emplea como medio para tratar diversos temas sin centrase en su figura, es decir, es una suerte de ente «traslucido» por el cual se observan los hechos que pasan en la sociedad (real o irreal) sin que su participación cobre relevancia (Alberca, 2007: 91). Hasta este punto, en Caballeriza se puede establecer el uso de esta trasparencia del personaje principal como medio para resaltar acciones de los demás personajes, en especial, las de la familia Carrión. La autoficción se convierte en facilitador de la narración; sirve como escondite para tratar temas delicados, sin que su participación llegue a tener relevancia y altere las acciones dadas en la narración; en este caso, la estratificación social y los delitos cometidos por las clases poderosas, con la necesidad de mantenerse en esa instancia en la que se encuentran.

Desde otro punto de vista, Casas (2011: 11) afirma que sí llega a existir una cierta influencia del papel de los autores de las obras autoficcionales en la medida en que intervienen en la recepción del texto por parte del lector y en las relaciones que se establecen entre ese autor y su yo autoficticio. Además, plantea una relación entre el receptor y el emisor, que puede ir más allá de lo textual, algo que es constatable en algunas de sus líneas: «-He leído, creo, todos sus libros - dijo, mientras yo guardaba la tarjeta - . Me gusta cómo escribe. Pero yo diría que nunca se ha metido de lleno en nuestra realidad. La de esta clase, quiero decir. Podría hacerlo ahora» (Rey Rosa, 2013: 241). 
En suma, el constante juego entre los distintos niveles narrativos metaficcionales perpetúan el desasosiego constante del lector: ¿qué de lo que me están contando es cierto?, ¿hasta dónde llega la imaginación del autor? Como se tratará en el siguiente apartado, muchos de estos elementos se ven reforzados con la continua proliferación de elementos paródicos en el transcurso de la trama.

\section{LA «NOVELA NEGRA EN CLAVE DE FARSA» O LA PARODIA DE LA INVESTIGACIÓN POLICIAL CLÁSICA}

La novela negra posiciona desde su germen elementos caóticos. Frente al acostumbrado intelectualismo y racionalismo acuñado al detective dentro de la tradición inglesa, producto, entre otras cosas, de las revoluciones industriales, el crecimiento abrupto de las urbes y el método analítico deudor del positivismo filosófico y científico (Gubern, 2002: 145); la variante negra norteamericana, por mencionar solamente una característica, choca de frente al proponer sujetos al ruedo de lo que «está sucediendo allá afuera». Así, la conceptualización que hace García Talaván en torno a la novela neopolicial latinoamericana es de vital importancia para el problema que se pretende abordar en este trabajo en tanto hereda de la novela negra una de sus características fundamentales: la constante revisión del género policiaco llegando incluso al cuestionamiento de las «normas preconcebidas» del género como forma para la regeneración y la ampliación de sus fronteras. Se utilizará el concepto general de parodia, entendida por Hutcheon y Rose (1979), citadas en Torres (2000), como:

[...] una imitación de uno o más modelos para someterlos, más tarde, a una subversión irónica por medio de un distanciamiento crítico. En este alejamiento el autor elabora un nuevo modelo que, aun evidenciando las huellas de los textos escogidos, revela las características de una obra nueva y original. (Torres, 2000: 404).

Desde punto de vista, la «novela negra en clave de farsa» de la que habla Rey Rosa puede insertarse en esta clasificación desde varias dimensiones: con el epígrafe inicial de este trabajo, es posible observar que el autor admite una influencia y a su vez un alejamiento consciente de los subgéneros históricos planteados por García Talaván, al tiempo que los deconstruye a 
través de procedimientos estéticos que están fuera del dogmatismo del policial, entendido bajo criterios claramente codificados en torno al enigma, al investigador y a la investigación misma. Estos criterios, como se pretende demostrar, serán subvertidos en Caballeriza.

Para Laorden, la novela clásica de enigma «presenta una sociedad armónica que se ve amenazada al cometerse un asesinato» (Laorden, 2015: 154). La sinopsis de la novela, de entrada, sugiere la idea de un relato de enigma en torno a un asesinato. En Caballeriza esta situación es presentada por el autor desde sus primeras páginas: el eje de la trama se sostiene alrededor del presunto atentado ocurrido en la finca de un terrateniente local, don Guido Carrión, durante su fiesta de cumpleaños, en la cual se hace presente un desfile de personalidades que, tal y como lo adelanta el autor, representa una especie de «microcosmos de la sociedad guatemalteca» (Rey Rosa, 2013: 291).

Rey Rosa - el protagonista - es un invitado más a esta fiesta, presencia de primera mano el altercado y posteriormente se embarca a investigarlo. ${ }^{19}$ Ante el desconcierto provocado por el siniestro el protagonista pregunta a un presente por lo sucedido: «Era el Duro II, el garañón de los cien mil, me aseguró un hombre de ojos vivos y pelo muy negro que vestía un traje de tres piezas» (Rey Rosa, 2013: 298). En este instante se comienza a llevar a cabo una relación de complicidad entre el protagonista y este interlocutor, que posteriormente se sabrá, es Jesús Hidalgo, abogado de la familia Carrión. El suceso sirve como incentivo para que el abogado le formule una propuesta al escritor: «Podría usted escribir un libro acerca de esto» (Rey Rosa, 2013: 299). Desde este momento la investigación criminal se plantea bajo una vertiente lúdica, es decir, el aliciente no es tanto la búsqueda del culpable como un tema interesante para escribir:

- Insisto, de aquí podría sacar material para un buen libro. Algo muy nuestro.

-Es posible - sonreí-. Su interés, supongo, es solamente literario.

19 Para Ricardo Piglia «[...] en la novela negra no parece haber otro criterio de verdad que la experiencia: el investigador se lanza, ciegamente, al encuentro de los hechos, se deja llevar por los acontecimientos y su investigación produce fatalmente nuevos crímenes; una cadena de acontecimientos cuyo efecto es el descubrimiento, el desciframiento» (Piglia, 2001: 60). 
- No, no solamente, tiene usted razón - replicó-. Tal vez lo hago por vanidad también. De cualquier forma, no pensaría en cobrarle - bromeóni en compartir la autoría. Pero claro, si me hiciera una dedicatoria, no me sentiría ofendido.

Nos reímos entre dientes, pero la idea comenzaba a interesarme.

(Rey Rosa, 2013: 299).

La alteración de este orden burgués-criollo aquí ya no se concibe como uno por reestablecer, en su lugar se plantea como una oportunidad para ampliar un bagaje escritural. A este respecto, el abogado le dice: «Me gusta cómo escribe. Pero yo diría que nunca se ha metido de lleno en nuestra realidad. La de esta clase, quiero decir. Podría hacerlo ahora» (Rey Rosa, 2013: 299). No cabe duda de que, a raíz de la conversación sostenida entre los dos personajes, entra en juego un factor de persuasión que provoca al escritor: «Cuando llegué a mi apartamento, yo estaba prácticamente convencido de que aquél era material para una historia» (Rey Rosa, 2013: 301). El interés por el asesinato queda, entonces, en segundo plano en tanto prima una necesidad creativa y utilitaria: «yo estaba en busca de algún tema para ponerme a escribir, y la idea me pareció interesante» (Rey Rosa, 2013: 289).

Por otra parte, en lo referente al investigador, Caballeriza se sale del convencional detective. En su lugar, el protagonista de esta novela se insertaría dentro de la tradición letrada que señala Quesada (2012: 178). Como se desarrolló en la sección anterior, el investigador resulta ser un escritor, además es posible observar que el mismo goza de legitimidad social a lo interno del círculo presente en la fiesta: «Alguno me felicitó por un artículo aparecido en la prensa o por algún libro que no había leído, pero de cuya publicación estaba enterado» (Rey Rosa; 2013: 295).

Rey Rosa, el escritor, ahora metido a investigador, cuenta con la complicidad del abogado para llevar a cabo la indagación. Juntos forman una pareja detectivesca muy particular, siendo que gran parte de la investigación es inducida por las observaciones del abogado, mismas que van dejándose de lado conforme al intercambio de impresiones entre ambos. En determinado momento, ante una pregunta de Rey Rosa, el abogado responde: «Digamos que sí, ya que estamos, ¿no es cierto?, haciendo ficción» (Rey Rosa, 2013: 
306). Se observa cómo en la reconstrucción del caso comienzan a primar verbos tales como «imaginemos», «supongamos», que remiten a una evolución ficcional de la investigación, dejándose de lado la lógica inductiva tradicional del investigador racional. La imaginación y la creación, en suma, relativizando aquel «superhombre mental» del género policial clásico sobre el que escribió Gubern (2002: 150).

\section{APUNTES FINALES}

Gran parte de la literatura centroamericana de la posguerra se caracteriza por experimentar con diversas formas estéticas y motivos introducidos en primera instancia por el neopolicial latinoamericano. No obstante, esta literatura a su vez dialoga y reelabora problemáticas referentes al contexto caótico resultante del ahora discutido regreso de la paz en la región durante la década de los noventa. Naturalmente, mucha de la producción de Rodrigo Rey Rosa puede estudiarse desde esa perspectiva.

El presente artículo argumenta que una de las reelaboraciones particulares de esta literatura se da en el campo de la autoficción, como recurso en gran medida deudor del peso que la narrativa testimonial tuvo durante el surgimiento de los movimientos revolucionarios y la lucha contra los autoritarismos en Centroamérica. En Caballeriza, este elemento se configura a través de un acercamiento del lector a la narración de los hechos, pretendiendo crear un lazo más íntimo y ambiguo entre el autor, el personaje y el lector mismo. El recurso autoficcional en Rey Rosa ya no tiene el carácter que otrora tuviera el testimonio. En su lugar es utilizado para plantear una interrogante en torno al mismo proceso creativo, insertándolo en una trama de misterio con consecuencias éticas y estéticas. Por un lado, no hay en la novela un compromiso militante, pero no por esto deja de lado el cuestionamiento al sistema social y político que todavía persiste en el país guatemalteco. Por otro, lleva a los límites el pacto ficcional creando con esto un espacio ambiguo con características lúdicas a través de la (re)adaptación de las formas policiales.

Estos factores lúdicos llegan a subvertir tanto los cánones clásicos del policiaco como los mismos desarrollados en los autores de neopolicial latinoamericano, aportando con esto nuevos elementos para el estudio de la novela centroamericana de posguerra. Los dos conceptos esenciales desarrollados 
en el trabajo constituyen una prueba de la vuelta a la ficción de la producción narrativa en el Istmo que señaló en su momento Ortiz-Wallner, siendo el neopolicial uno de los géneros predilectos para este retorno. La cita que forma parte del título de este artículo engloba el hecho problemático de producir una narrativa en clave policiaca desde países como los centroamericanos, los cuales siguen presentando dificultades para alcanzar cuotas satisfactorias de inserción y cohesión social; en suma, «se hace lo que se puede y con lo que se tiene a mano».

\section{REFERENCIAS BIBLIOGRÁFICAS}

AlberCa, Manuel (2005), «¿Existe la autoficción hispanoamericana?», en Cuadernos del CILHA, 7, págs. 5-17.

- (2007), «iÉste (no) soy yo? Identidad y autoficción», en Pasajes, 25, págs. 88-101.

Argueta, Manlio (1985), Un día en la vida, San José, EDUCA.

BeVerley, John (1987), «Anatomía del testimonio», en Revista de Crítica Literaria Latinoamericana, 13(25), págs. 7-16.

BoLAÑo, Roberto (2004), Entre paréntesis, Barcelona, Editorial Anagrama.

Bouvet, Françoise (2015), «La novela sicaresca colombiana o la crónica de una Muerte ordinaria», en Amerika, 12. Disponible en: http://journals. openedition.org/amerika/6447

CABEZAs, Omar (1982), La montaña es algo más que una inmensa estepa verde, Managua, Editorial Nueva Nicaragua.

CASAS, Ana (2011), «La autoficción en los estudios hispánicos: perspectivas actuales», en Ana Casas (ed.), El yo fabulado. Nuevas aproximaciones críticas a la autoficción, Madrid / Frankfurt, Iberoamericana Editorial Vervuert, págs. 7-21.

Coello, Emiliano (2008), «Variantes del género negro en la novela centroamericana actual», en Istmo: Revista virtual de estudios literarios y culturales centroamericanos, 17. Disponible en: http://istmo.denison.edu/n17/proyectos/coello.html 
- (2009), «El pícaro como protagonista en las novelas neopoliciales de Rafael Menjívar Ochoa y Horacio Castellanos Moya», en Centroamericana, 17, págs. 5-19.

CORTÉz, Beatriz (2000), «Estética del cinismo: la ficción centroamericana de posguerra», en Revista Áncora. Disponible en: http://wvw.nacion.com/ ancora/2001/marzo/11/historia3.html

GaLindo, Juan Carlos (2018), “'Country noir', el asesino está en el campo», El País. Disponible en: https://elpais.com/cultura/2018/04/08/actualidad/1523139170_638490.html

García TAlaVÁn, Paula (2014), «La novela neopolicial latinoamericana: una revuelta ético-estética del género», en Cuadernos Americanos, 148(2), págs. 63-85.

Gubern, Román (2002), Máscaras de la ficción, Barcelona, Anagrama.

Guzman-Medrano, Gael (2013), Post-Revolutionary Post-Modernism: Central American Detective Fiction by the Turn of the 21st Century (Dissertation for the degree of Doctor of Philosophy in Spanish), Florida International University. Disponible en: http:// digitalcommons.fiu.edu/etd/917

HERNÁNDEZ, Víctor (2015), La violencia en la narrativa de Rodrigo Rey Rosa (Trabajo de Fin de Máster en Lengua Española, Literatura Hispánica y ELE), Universitat Autònoma de Barcelona. Disponible en: http://www.recercat.cat/ / handle/2072/257755

Кокотоугс, Misha (2003), «After the Revolution: Central American Literature in the Age of Neoliberalism», en A Contracorriente. A Journal of Social History and Literature in Latin America, 1(1), págs. 19-50.

- (2006), «Neoliberal Noir: Contemporary Central American Crime Fiction as Social Criticis», en Clues. A Journal of Detection, 24(3), págs. 15-29.

- (2012), «Neoliberalismo y novela negra en la posguerra centroamericana», en Beatriz Cortéz, Alexandra Ortiz-Wallner y Verónica Ríos (eds.), Hacia una historia de las literaturas centroamericanas. (Per)versiones de la modernidad. Literaturas, identidades y desplazamientos, Guatemala, F\&G Editores, págs. 185-209. 
LAORDEN, María T. (2015), «Ni Marlowe ni Sherlock. Violencia y novela policíaca en tres ejemplos centroamericanos», en Philobiblion. Revista de literaturas hispánicas, 1, págs. 153-164.

LeYva, Héctor M. (2016), «Desborde emocional y ficción ética en las novelas centroamericanas de guerrilleros», en Revista Realidad, 148, págs. 61-80.

MACKENBACH, Werner (2007), «Entre política, historia y ficción. Tendencias en la narrativa centroamericana a finales del siglo XX», en Istmo. Revista virtual de estudios literarios y culturales centroamericanos, 15. Disponible en: http://istmo.denison.edu/n15/articulos/mackenbach.html

Martín, Álex M., y SÁnchez Zapatero, Javier (2007), «Una mirada al neopolicial latinoamericano: Mempo Giardinelli, Leonardo Padura y Paco Ignacio Taibo II», en Anales de Literatura Hispanoamericana, 36, págs. 49-58.

Martínez-Barahona, Elena., Gutiérrez, Martha., y Rincón, Liliana (2012), «Impunidad en El Salvador y Guatemala: “de la locura a la esperanza: ¿nunca más"», en América Latina Hoy, 61, págs. 101-136.

Menchú, Rigoberta / Burgos, Elizabeth (1985), Me llamo Rigoberta Menchú y así me nació la conciencia, México, Siglo XXI Editores.

Michael, Joachim (2013), «Narco-violencia y literatura en México», en Sociologias, 15(34), págs. 44-75.

MONTERROSO, Arturo (2011), «Yo, el protagonista. La autoficción en una novela de Rodrigo Rey Rosa», en Centroamericana, 20, págs. 119-127.

Noguerol, Francisca (2006), «Neopolicial latinoamericano: el triunfo del asesino», en Ciberletras: Revista de crítica literaria y de cultura, 15, págs. 1-15.

ORTIZ-WALLNER, Alexandra (2012), El arte de ficcionar: la novela contemporánea en Centroamérica, Madrid, Iberoamericana Editorial Vervuert.

PAdURA, Leonardo (1999), «Modernidad y postmodernidad: La novela policial en Iberoamérica», en Hispamérica. Revista de Literatura, 84, págs. 37-50.

Perkowska, Magdalena (2011), «La infamia de las historias y la ética de la escritura en la novela centroamericana contemporánea», en Istmo: Revista virtual de estudios literarios y culturales centroamericanos, 22. Disponible 
en: http://istmo.denison.edu/n22/articulos/24_perkowska_magdalena_form.pdf

PezzĖ, Andrea (2011), «El complot que se repite: la Centroamérica de Horacio Castellanos Moya y Rodrigo Rey Rosa», en Polifonía Scholarly Journal, 1(1), págs. 13-25.

- (2018), «El neopolicial centroamericano y sus clásicos», en Àlex Martín Escribà y Javier Sánchez Zapatero (eds.), Clásicos y contemporáneos en el género negro, Santiago de Compostela, Andavira Editora, págs. 219-226.

Piglia, Ricardo (2001), Crítica y ficción, Barcelona, Editorial Anagrama.

Pozo, Antonio (2017), «Autoficción en la novela: realidad, ficción y autobiografía», en Impossibilia. Revista Internacional de Estudios Literarios, 13, págs. $1-20$.

QuesADA, Uriel (2012a), «¿Por qué estos crímenes? Literatura policiaca en Centroamérica», en Beatriz Cortéz, Alexandra Ortiz-Wallner y Verónica Ríos (eds.), Hacia una historia de las literaturas centroamericanas. (Per)versiones de la modernidad. Literaturas, identidades y desplazamientos, Guatemala: F\&G Editores, págs. 165-183.

- (2012b), «De Castigo Divino a El cielo llora por mí: 20 años del Neopolicial centroamericano», en Brigitte Adriaensen y Valeria Grinberg Pla (eds.), Narrativas del crimen en América Latina: transformaciones y transculturaciones del policial, Münster: Lit Verlag, págs. 59-74.

QuinTERO, Julio (2015), «Comprender y novelar el archivo: El material humano de Rodrigo Rey Rosa», en Istmo: Revista virtual de estudios literarios y culturales centroamericanos, 31. Disponible en: http://istmo.denison.edu/ n31/articulos/10_quintero_julio_form.pdf

Ramírez, Sergio (1988), Castigo divino, Madrid, Mondadori.

Rey Rosa, Rodrigo (1995), El cojo bueno, Madrid, Alfaguara.

- (1996). Que me maten si..., Guatemala, Ediciones del Pensativo.

- (2001). Piedras encantadas, Barcelona, Seix Barral. 
- (2006). Caballeriza, Barcelona, Seix Barral.

- (2009). El material humano, Barcelona, Anagrama.

- (2013). Imitación de Guatemala, México, Alfaguara.

RiverA, Ronald (2014), «Propuestas narrativas de la nueva literatura centroamericana: la novela policial», en Pensamiento Actual, 14(22), págs. 55-63.

Rodríguez Freire, Raúl (2011), «Escritura en movimiento: entrevista con Rodrigo Rey Rosa», en Revista Iberoamericana, 27(236-237), págs. 1073-1082.

Rosales, Miroslava (2016), «Configuraciones y autoconfiguración de Rodrigo Rey Rosa», en Istmo: Revista virtual de estudios literarios y culturales centroamericanos, 33. Disponible en: http://istmo.denison.edu/n33/articulos/12.html

SÁnChez ZAPATERo, Javier (2017), «Poéticas criminales: reflexiones teóricas de escritores de novela negra y policiaca», en Tropelías. Revista de Teoría de la Literatura y Literatura Comparada, número extraordinario, 2, págs. 120-132.

SCARANO, Laura (2017), «Escribo que escribo: de la metapoesía a las autopoéticas», en Tropelías. Revista de Teoría de la Literatura y Literatura Comparada, número extraordinario, 2, págs. 133-152.

Soто, Mariana (2016), «El policial no se crea ni se destruye, solo se transforma: construcción de identidad y desencanto en Paisaje de Otoño de Leonardo Padura», en Istmo: Revista virtual de estudios literarios y culturales centroamericanos, 32. Disponible en: http://istmo.denison.edu/n32/proyectos/05_soto_mariana_form.pdf

TORRES, Inmaculada (2001), «Parodia y novela policiaca en La hija del caníbal de Rosa Montero», en, Congreso Nacional Literatura y Sociedad, Literatura y sociedad, el papel de la literatura en el siglo XX. España, Universidade da Coruña, págs. 401-413.

Torres-Rivas, Edelberto (2008), «Guatemala 2000: un edificio de cinco pisos (Introducción a un análisis de estratificación social)», en Edelberto Torres-Rivas, Centroamérica: entre revoluciones y democracia, Bogotá, CLACSO / Siglo del Hombre Editores, págs. 283-298. 


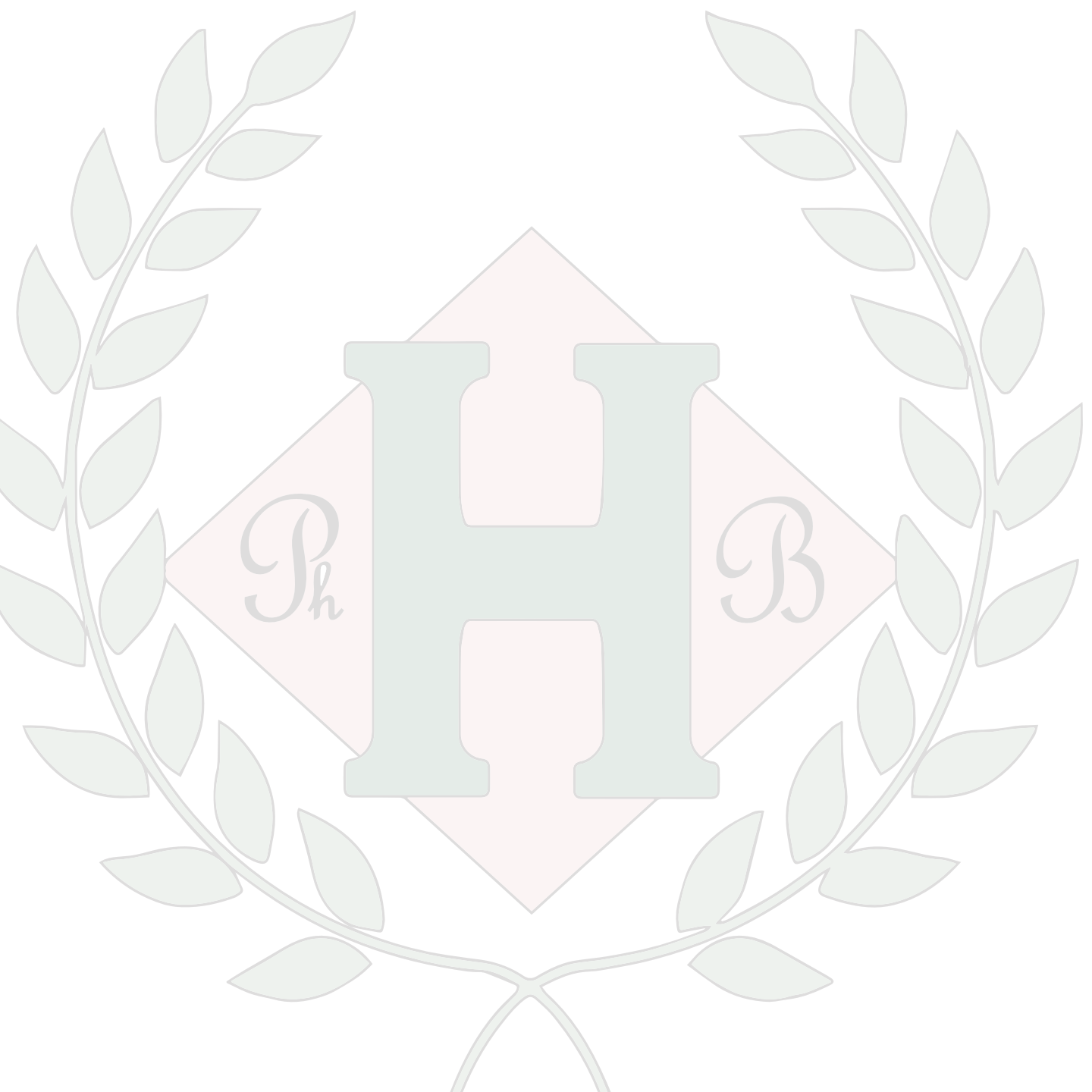

